\title{
Measuring blast fragmentation at Esperanza mine using high resolution 3D laser scanning
}

\author{
Dr Italo Onederra \\ School of Mechanical and Mining Engineering, CRC Mining \\ The University of Queensland, Australia \\ $\mathrm{T}+61733654780 \bullet \mathrm{M}+61408133324 \bullet$ \\ Ei.onederra@uq.edu.au
}

\begin{abstract}
Associate Professor Matthew Thurley
Principal - Innovative Machine Vision Pty Ltd, Melbourne, Australia

Associate Professor Image Analysis - Luleå University of Technology, Sweden imv@imv.net.au, matthew.thurley@1tu.se
\end{abstract}

\section{Mr Alex Catalan}

Geotechnical Expert

Gerencia Técnica de Minería

Vicepresidencia de Operaciones

Antofagasta Minerals S.A.

acatalan@aminerals.cl 


\title{
Measuring blast fragmentation at Esperanza mine using high resolution 3D laser scanning
}

\author{
I. Onederra ${ }^{1}$, M. Thurley ${ }^{2,3}$ \& A. Catalan ${ }^{4}$ \\ ${ }^{1}$ School of Mechanical and Mining Engineering, CRCMining, The University of \\ Queensland, Brisbane, Qld, Australia. \\ ${ }^{2}$ Innovative Machine Vision Pty Ltd, Melbourne, Australia, \\ ${ }^{3}$ Luleå University of Technology, Luleå, Sweden \\ ${ }^{4}$ Antofagasta Minerals Group, Santiago, Chile
}

\section{Synopsis}

Image analysis as a technique for fragmentation measurement of rock piles has been the subject of research since the 1980's and to date, run of mine (ROM) fragmentation optimisation studies have primarily relied on particle size measurement using photographic based 2D imaging systems. Disadvantages of 2D imaging systems include particle delineation errors due to variable lighting and material colour and texture variation; no direct measure of scale \& perspective distortion; and inability to distinguish overlapped particles, non-overlapped particles and areas-of-fines. With the development of 3D imaging technologies, there is an opportunity to develop techniques that could improve data collection and overcome the limitations of existing 2D image based systems. This paper describes the first attempt to use 3D high resolution laser scanning techniques to quantify "whole of muckpile" fragmentation from full scale production blasting. During two monitoring campaigns in 2013, high resolution laser scanning data was collected from production blasts at Esperanza Mine (Antofagasta Minerals Group). Fully automated analysis of the 3D data was possible in all cases where the data was of sufficiently high resolution. Manual pre-processing was required when the data was of low resolution to specify the region of fines. Overall results indicated that run of mine fragmentation requirements were meeting specified targets despite the marked differences in powder factors. This was particularly the case for those blasts conducted in similar geological domains. This work has demonstrated that high resolution laser scanning can be used as an alternative technique to measure "whole of muckpile" fragmentation in production blasting.

\section{Introduction}

For a number of years, both researchers and practising engineers have been aware of the importance of being able to tailor blast fragmentation to optimise the overall mineral extraction and recovery processes. In mining and quarrying, there is evidence to suggest that by providing an appropriate size distribution to crushing and grinding circuits, a measurable increased throughput and/or reduced power draw can be obtained. In a process integration/optimisation approach (e.g. Mine to Mill), measuring run of mine (ROM) blast fragmentation is necessary for model calibration purposes and their subsequent application in scenario based simulations (Onederra et al., 2010).

Image analysis as a technique for fragmentation measurement of rock piles has been the subject of research since the 1980's (Carlson \& Nyberg 1983, Ord 1988) and to date fragmentation optimisation studies have primarily relied on particle size measurement using photographic based 2D imaging systems. The 2012 Fragblast workshop on Measurement and Analysis of Blast Fragmentation provides several current examples of fragmentation measurement for blast assessment (Venkatesh et.al 2013, Delille et.al 2013 and correspondence with Delille). These are entirely based on 2D photographic imaging and are all image analysis systems that perform a 
particle delineation that then requires "manual editing to insert missing boundaries between fused fragments, and to delete false edges where a fragment has disintegrated into two or more pieces" (Venkatesh et.al 2013).

The disadvantages of 2D photographic systems are significant and have been noted variously by Thurley \& Ng (2005), Thurley (2012) and Noy (2013) and include:

- Severe particle delineation errors due to uneven lighting conditions which can be extreme outdoors, excessive shadowing; and/or colour and texture variation in the material

- no direct measure of scale \& perspective distortion

- lack the capability to distinguish between overlapped and non-overlapped particles, and;

- an inability to automatically detect visible fines in a realistic way.

In their review of another commercial photographic based 2D system Potts \& Ouchterlony (2005) express strong reservations saying that: " $2 \mathrm{D}$ imaging has a certain but limited usefulness when measuring the fragment size distribution in a muckpile or from a belt in an accurate way. It could probably detect rough tendencies in fragmentation variations, if the lighting conditions do not vary too much, and if cover glasses for camera lenses are kept clean". In addition, they report that for their application the system erroneously "causes the truncated, bimodal distributions to, in a misleading way, show up as unimodal curves. This implies a strong limitation of the system's ability to detect changes in the form of the fragment size distribution".

In the open-pit environment used here, variation in lighting conditions can be extreme and in the authors opinion ensures 2D photographic imaging can only be highly erroneous without substantial manual particle delineation, which in itself introduces inconsistencies due to the human operator.

Furthermore we note that, using a fragmentation assessment system that cannot detect a bimodal distribution, will most likely prevent detection of one when it is present. Therefore the choice of a fragmentation assessment system comes down to how much one can trust a system that forces a type of distribution, instead of trying to represent the actual fragmentation in the images taken.

With the development and further accessibility of 3D imaging technology, there is an opportunity to develop techniques that could overcome the limitations of existing 2D image based systems. This can include the ability to obtain data without the influence of lighting conditions; shadowing or texture differences, and the ability to automatically delineate particles without the need for manual editing. Furthermore, 3D data provides a direct measure of scale; and as demonstrated by Thurley \& Ng $(2005,2008)$, and Thurley $(2009,2013)$ provides the ability to classify delineated regions as overlapped particles, non-overlapped particles, or areas-of-fines, size these different classes of material in different ways, and output size distributions based on volume information.

There have been very few publications relating to particle size measurement using 3D imaging in an open-pit environment (Noy, 2013; Thurley, 2013). Noy (2013) presents work on a stereo camera setup attached to a shovel and discusses many of the difficulties getting a system to work well in such an environment. Noy calibrates the measurements against sieving data and no examples of the particle delineation are provided.

The presented work, based on Thurley (2013), calculates the size of the non-overlapped particles and the areas-of-fines without statistical remapping to an expected size distribution and the 
assumptions this implies (Potts \& Ouchterlony 2005). Furthermore, examples of the particle delineation results are shown and the particle delineation is classified into non-overlapped rocks, overlapped rocks, and areas-of-fines. Thurley provides the only published algorithms (Thurley \& $\mathrm{Ng}, 2008$; Thurley 2009) to remove the bias resulting from mis-sizing overlapped particles as if they were smaller non-overlapped particles, and to detect areas of fines.

There are also additional sources of error relevant to any measurement system that collects a "sample" or image from the visible surface. The most significant of these is Segregation and Grouping error, also known as the Brazil-nut effect (Rosato et. al. 1987), where a pile of rocks has a tendency to segregate into material of different sizes when subjected to vibration. Whilst this is not an appropriate description of blasting, it is also not reasonable to assume that the blast homogenises the rock pile. Therefore the pile surface at any given moment is not expected to be represented of the entire pile. Therefore, in order to collect a representative and statistically significant sample, measurement during different stages of the material extraction has been performed for each blast.

This paper presents the data collection and analysis to evaluate run of mine (ROM) blast fragmentation. During two monitoring campaigns in 2013, high resolution laser scanning data was collected in two phases of production at Esperanza Mine (Antofagasta Minerals Group) in northern Chile. This paper describes the background, and results from this comprehensive blast fragmentation monitoring campaign.

\section{Esperanza Mine, Chile}

Esperanza is a large open pit copper and gold mine located 30 kilometers from Sierra Gorda community of the Antofagasta Region in Chile (Figure 1). During its first ten years of operations, it will produce approximately 190 thousand tons of copper concentrates and 230 thousand pounds of gold as its main by-product. The project construction started in mid-2008, and its start-up period in November 2010. Reserves are estimated in 587 million tons with an average copper grade of $0.53 \%$ and more than 0.22 grams of gold per ton. The project involved a total investment of US\$ 2.7 billion. Figure 2 shows an image of the open pit mine.

Two comprehensive blast performance monitoring campaigns were conducted at Esperanza mine. The first was carried out during January through to March 2013, focusing on three production blasts with an average powder factor of $480 \mathrm{~g} / \mathrm{t}$ in $16 \mathrm{~m}$ high benches. A total of 58 scans from these three muckpiles were processed in this particular stage. The second campaign was conducted during the months of October and November 2013, focusing on another set of production blasts with an average powder factor of $360 \mathrm{~g} / \mathrm{t}$. In this case a total of $37 \mathrm{scans}$ from these three muckpiles were processed. 


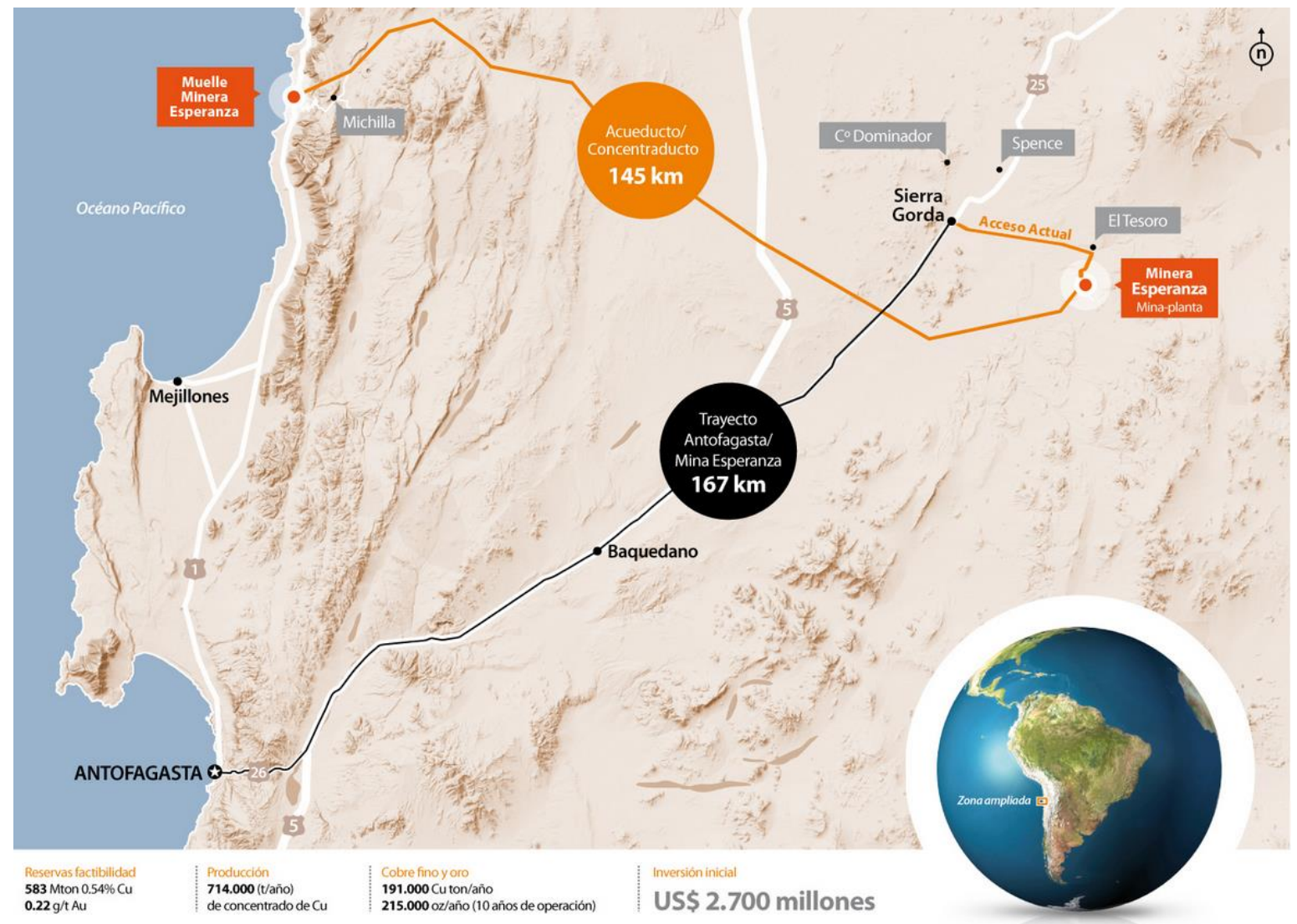

Figure 1. Location of Esperanza Mine (Antofagasta Minerals, 2014)

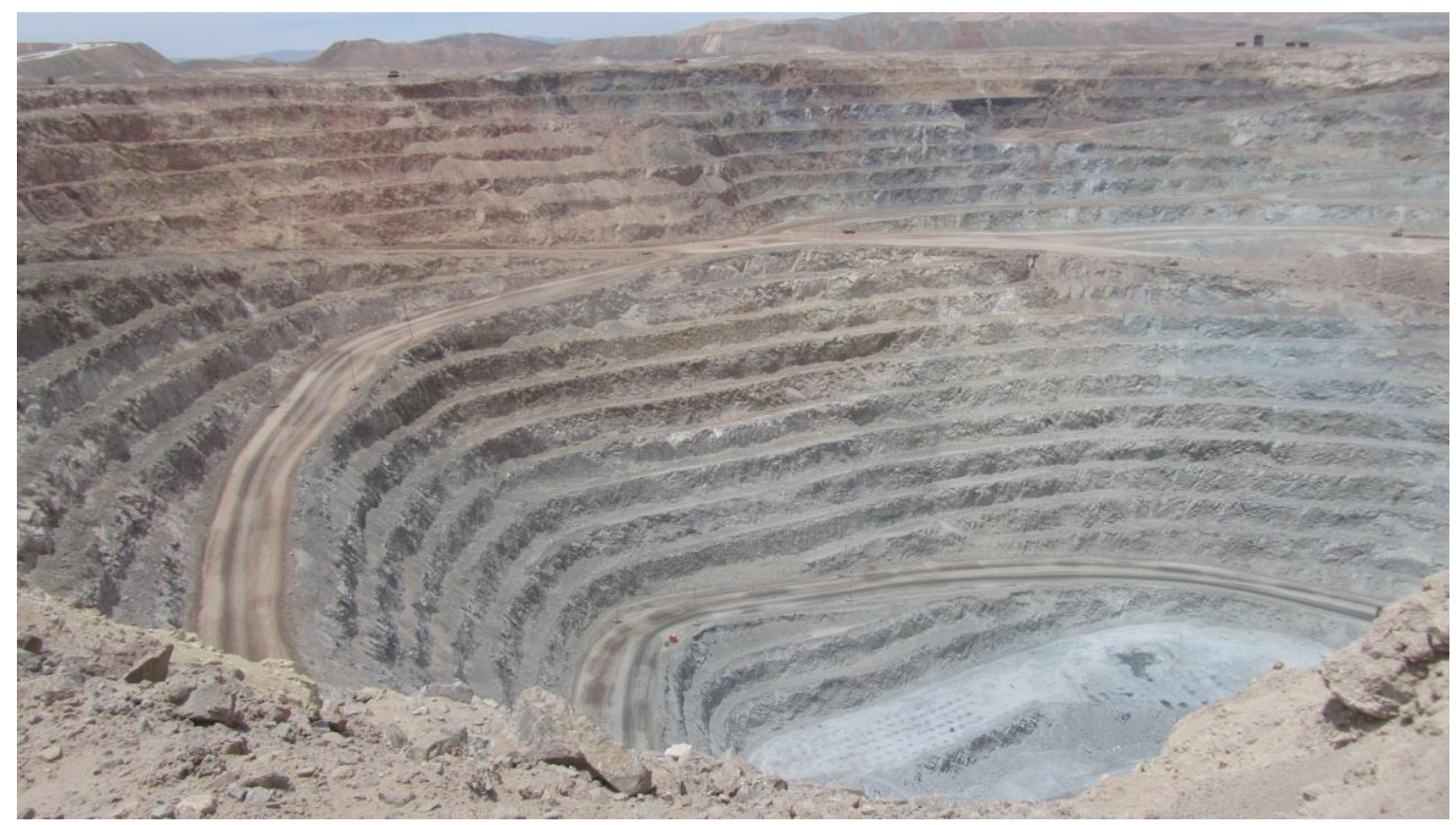

Figure 2. View of Esperanza pit and blasting practices near final walls of Phase 02 


\section{Method of data collection and analysis}

The data analysis process has been adapted from earlier developments in laser scanning of materials in conveyor belts (Thurley, 2012) and LHD buckets (Thurley 2009). This new adaptation used site specific data collection procedures which considered both site access and the main specifications of the laser scanning system available. The data collection described in this paper was performed in collaboration with Esperanza mine personnel; and used the 8810 series I-site Maptek laser scanning system (Maptek, 2014). The procedures implemented at Esperanza mine ensured that scans were performed at regular intervals during the excavation cycle. The principal aim was to obtain data from the front, middle and back sections of each muckpile. Scanning was conducted immediately after the blast and at intervals that minimised interference with production activities. However, there were few instances where data collection was prioritised in order to maintain sampling consistency.

\subsection{Measurement Hardware}

The Maptek I-Site 8810 scanner is generally used for mapping the geometry of the open-pit and collect data for pit design geometry reconciliation and subsequent geotechnical analysis. The product specifications state a minimum angular step size of $0.0125^{\circ}$ and a beam divergence of $0.25 \mathrm{mrad}$ (approx. $0.014^{\circ}$ ). The beam divergence is only slightly larger than the angular step size, so the spot size of the laser at any given point will be quite similar to the distance between that point and its neighbouring points. A more detailed list of specifications is shown in table 1 . This very small angular resolution of $0.0125^{\circ}$ makes the I-Site scanner suitable for collecting high density 3D surface "images" of rock piles suitable for fragmentation measurement.

Rocks that are further away from the scanner will have fewer measured 3D points on them, meaning smaller rocks will be less able to be detected the further away they are.

Table 1 : Maptek I-Site 8810 Laser Scanner Specifications

\begin{tabular}{ll}
\hline Maximum range & Up to $500 \mathrm{~m}$ with reflectivity > $10 \%$ \\
Range accuracy & $10 \mathrm{~mm}$ \\
Range repeatability & $18 \mathrm{~mm}$ \\
Beam divergence & $0.25 \mathrm{mrad}$ (approx. $0.014^{\circ}$ ) \\
Angular step size & $0.2^{\circ}$ to $0.0125^{\circ}$ \\
Angular accuracy & $0.01^{\circ}$ \\
Angular scanning range & $80^{\circ}$ vertical, $360^{\circ}$ horizontal \\
\hline
\end{tabular}

In reference to Figure 3, the data collection scanning procedure included the following components:

- Scanning muckpiles at different intervals and regions during the excavation process.

- Scanning part of the muckpile from close range (approximately $9 \mathrm{~m}$ ) for fine resolution scans, and

- Scanning the full height of the pile (or close to) at longer range (approximately $20 \mathrm{~m})$ for coarse resolution scans.

Looking at a pile at a high angle will make the scanned data of lower spatial resolution and therefore less able to detect smaller rocks. The scan sequence was set at 13 degrees left and 13 degrees right; and 20 degrees up and 5 degrees down. The angles were chosen to select the close- 
range highest resolution portion of the data and to ignore as much as possible the pit floor in order to avoid manual cropping and pre-processing steps.

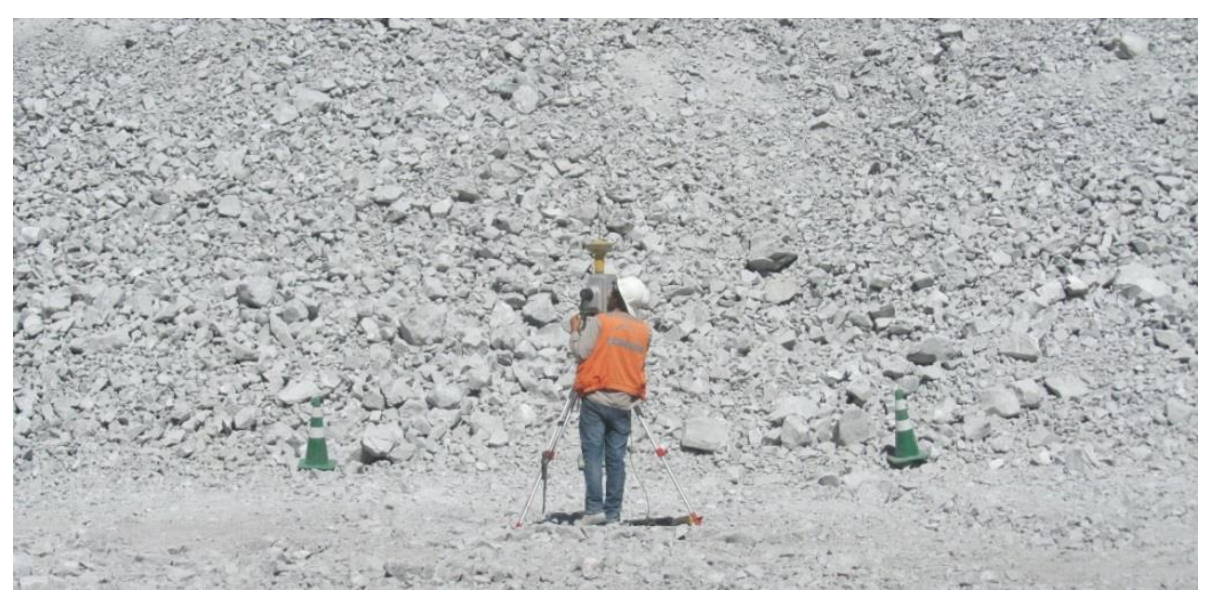

Figure 3. Example of laser scanner positioning

\subsection{Measurement Geometry}

One of the key criteria for particle size measurement is high data density as it defines the capacity to detect small overlapped particles, the lower limit on particle size that can be reliably detected, and the resolution of size classes detectable. Therefore understanding the expected spatial distance between measured 3D points is important.

The measurement geometry is illustrated in Figure 4 which in the field closely refers to Figure 3. In this approach, the measured data is further cropped to $\pm 12^{\circ}$ in the horizontal plane and $-5^{\circ}$ to $+12^{\circ}$ in the vertical plane. There is no special reason for choosing precisely $12^{\circ}$ but it was chosen as a balance between a high spatial resolution of 3D points and a sufficiently large field of view of the rock pile.

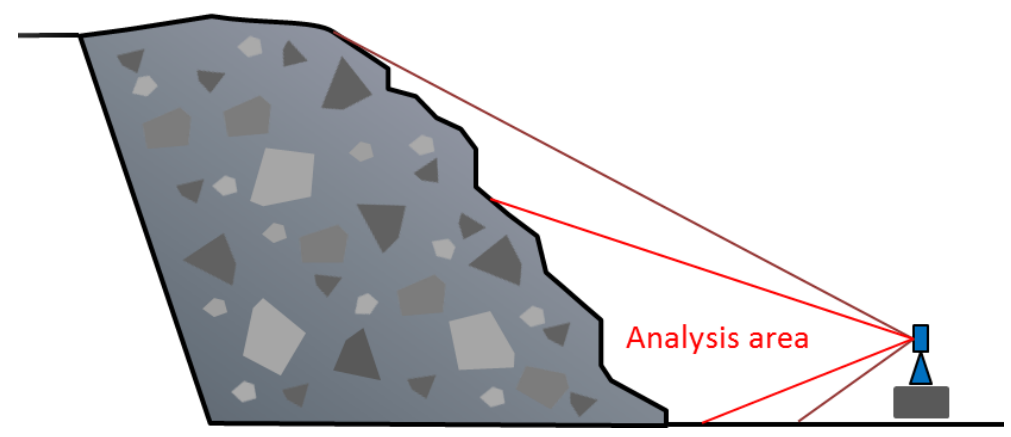

Figure 4: Measurement Geometry and Analysis Area

Considering a sample cropped measured data set with 2.4 million 3D points which we denote set A (as shown in Figure 6), and that this data set exists in a right handed coordinate system with the positive $\mathrm{z}$ axis being a horizontal line from the rock pile to the laser scanner, and the $\mathrm{x}, \mathrm{y}$ image plane perpendicular to the $\mathrm{z}$ axis. We note that set $\mathrm{A}$ is a data set with a roughly fixed angular resolution (subject to an angular accuracy of $0.01^{\circ}$ ) but an increasing spatial resolution $\Delta \mathrm{x}$ and $\Delta \mathrm{y}$ in the image plane between neighbouring 3D points. Set A (Figure 6) has an extent of $[-4.657 \mathrm{~m}$, $4.752 \mathrm{~m}]$ in the $\mathrm{x}$ axis, $[-1.689 \mathrm{~m}, 5.304 \mathrm{~m}]$ in the $\mathrm{y}$ axis, and $[-24.923 \mathrm{~m},-9.311 \mathrm{~m}]$ in the $\mathrm{z}$ axis, where 
the laser scanner is positioned at the origin. Using trigonometry the distance measures between neighbouring points can be considered in the simple case. At a distance of $10 \mathrm{~m}$ from a vertical wall, with a horizontal angle of $0^{\circ}$, and vertical angles of $0^{\circ}$ and $0.0125^{\circ}$ the corresponding $\Delta y$ distance is $2.2 \mathrm{~mm}$. If the vertical angles are increased to $11.9875^{\circ}$ and $12^{\circ}$ then the $\Delta \mathrm{y}$ distance is $2.3 \mathrm{~mm}$. But this is the best case of a perpendicular surface to the scanner and the worst case is less trivial as the scanner is measuring values on the rock pile which is inclined away in the $y$ axis.

Given the known extents of set A, we convert Figure 4 into a simple geometric representation of the $\mathrm{y}, \mathrm{z}$ plane as shown in Figure 5 (not to scale). This figure depicts the laser scanner at the origin $\mathrm{O}$, the rock pile approximated by the triangle $\Delta \mathrm{Q} 1 \mathrm{P} 1 \mathrm{~B}$, and the dashed line OQ2 from the laser scanner intersecting the surface of the rock pile at R. Using simple trigonometry the length of the line HQ2, and the angles $L Q 1 O H$, and $L Q 1 P 1 B$ have been pre-calculated. Although the angle $\left\llcorner\mathrm{Q} 1 \mathrm{OH}\right.$ is not exactly $12^{\circ}$ as expected it is within the angular accuracy given in Table 1 . What is of interest is the maximum $\Delta \mathrm{y}$ which will be found between points $\mathrm{R}$ and Q1. Using the parametric equations of a line the intersection of the lines OQ2 and P1Q1 can be calculated. The result is that $\mathrm{R}$ is positioned at $(\mathrm{z}, \mathrm{y})=(-24.889 \mathrm{~m}, 5.289 \mathrm{~m})$, and the $\Delta \mathrm{y}$ between $\mathrm{R}$ and Q1 is therefore $15 \mathrm{~mm}$ and the length of the line RQ1 is $37 \mathrm{~mm}$.

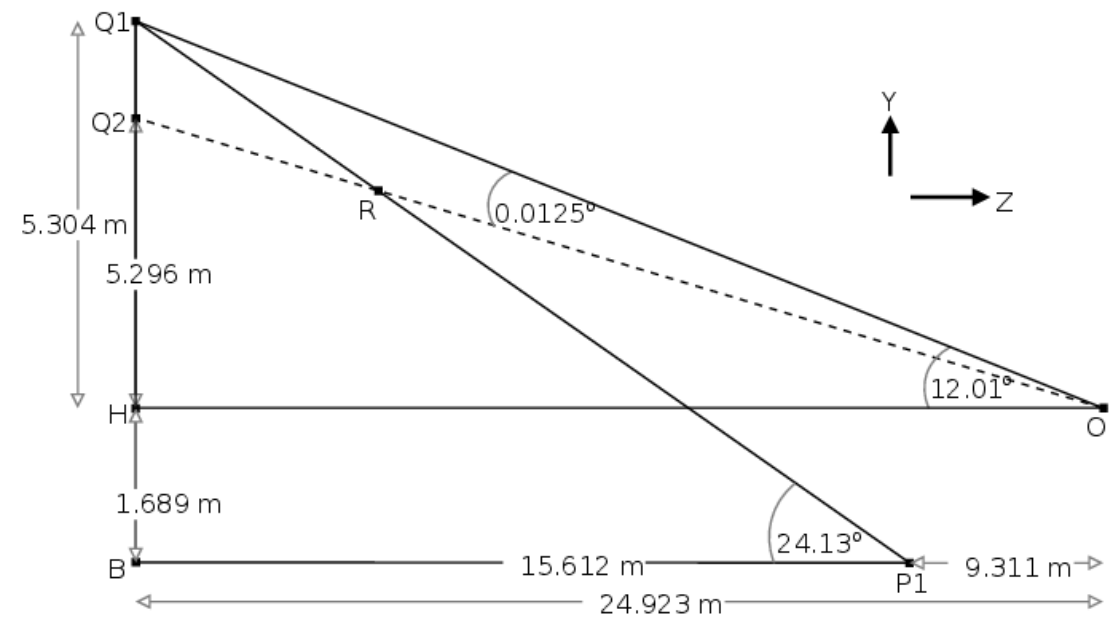

Figure 5: Measurement Geometry for an example data set (Set A) not drawn to scale.

From experience of analysing 3D profile data of piled particles (Thurley 2009, 2011, 2012), the expectation is that particles in a pile can be reliably detected at a size of approximately 10 times the spacing between points in the image plane. Therefore, for set $\mathrm{A}$ with $3 \mathrm{D}$ data points with a $\Delta \mathrm{y}$ ranging between $2.2 \mathrm{~mm}$ and $15 \mathrm{~mm}$, the expectation is to detect particles larger than $22 \mathrm{~mm}$ at the area of highest point density, and larger than $150 \mathrm{~mm}$ in the areas of lowest point density. Unfortunately this upper limit is higher than would be preferred. The only way to improve this with the current system is to change the measurement geometry by being closer to the pile. This may not always be possible in operational environments. Further research is required to evaluate imaging systems that could be mounted on excavators or shovels that are always in close proximity to the pile.

The beam divergence of the laser is only slightly larger than the angular resolution, so we can expect that the beam spot size is similar to the values calculated here, with a beam size of the surface of the pile slightly larger than $37 \mathrm{~mm}$ in the worst case. The implication being that the 3D point calculated in this case is some weighted average value of the rocks in a circular area slightly 
larger than $37 \mathrm{~mm}$ diameter. This will add a smoothing to the data, blurring the edges and likely making particle segmentation more difficult in these areas.

\subsection{Processing}

The data processing methodology is an entirely automatic process with no manual intervention and consisted of the following steps:

1. Processing the range data to $\mathrm{x}, \mathrm{y}, \mathrm{z}$ and row, column ordering based on the laser scan lines

2. Cropping the bottom $500 \mathrm{~mm}$ off the vertical axis to ensure the pit floor has been removed.

3. Filtering to remove erroneous $3 \mathrm{D}$ points and interpolating missing $3 \mathrm{D}$ points

4. Orthogonally re-projecting the data

5. Performing particle delineation

6. Back projecting the data to the original perspective projection

7. Sizing

The particle delineation approach is based on watershed segmentation and morphological operators. The following is an overview of the analysis approach with detail presented in Thurley (2013).

Pre-processing is performed to remove the erroneous rays of data points that can occur in the laser data. These rays of 3D data points appear in vertical columns of data and arc up from the rock pile surface and remain above the pile surface. These are removed using a minimum filter.

Particle delineation is performed using the following stages;

1. Edge detection is performed using a morphological gradient with a spherical structuring element and then thresholded to classify edges.

2. Seed formation for the watershed segmentation is performed using a three step process based on distance transform, local maxima, and seed merging.

3. Watershed segmentation based on the seed regions is applied to the rock pile data after which a filter is applied to remove small "noise" regions.

The classification of delineated regions into non-overlapped rocks, and areas-of fines is based on algorithms developed by Thurley $(2008,2009)$. These algorithms examine each region in the segmentation and perform a neighbourhood based analysis of the 3D information around the perimeter of each particle. Sizing is performed by calculating an elliptical volume for each identified non-overlapped rock and a bulk volume for the combined areas-of-fines using a constant depth parameter. Four test measurements were used to determine this parameter which was used in all subsequent analysis. Although this pragmatic approach can be sufficient for making relative comparisons of fragmentation outcomes; it has a number of limitations, particularly if prior calibrations have not been adequately conducted. Further work is currently underway to establish a procedure that involves estimating fines with measurements taken from both the source muckpile and the primary crusher product. This procedure will use available laser based fragmentation analysis technology on conveyor belts (Thurley, 2012) and material tracking devices.

Figure 6 shows the raw data; this is processed to produce the orthogonal projection shown in Figure 7. Figure 8 shows the automatic classification result for regions identified as areas-of-fines. Figure 
9 shows the automatic particle delineation for Figure 7, with a magnified area of the delineation shown in Figure 10.

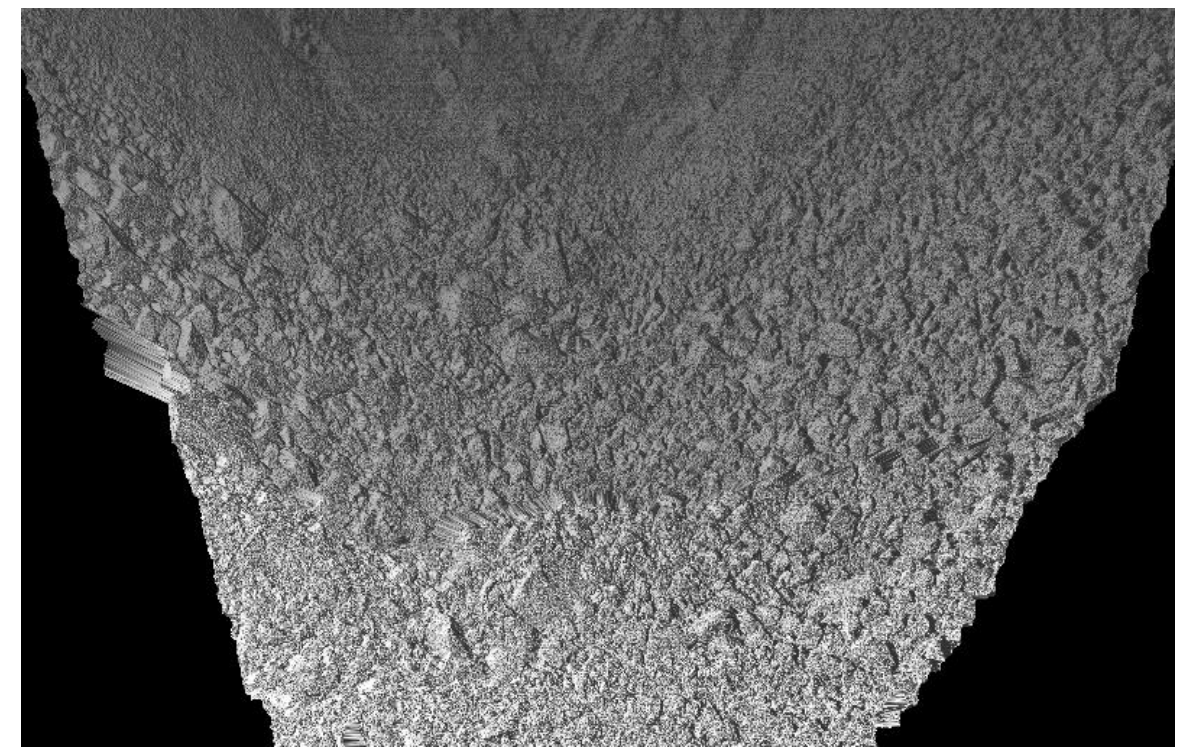

Figure 6. Raw data from a muckpile laser scan

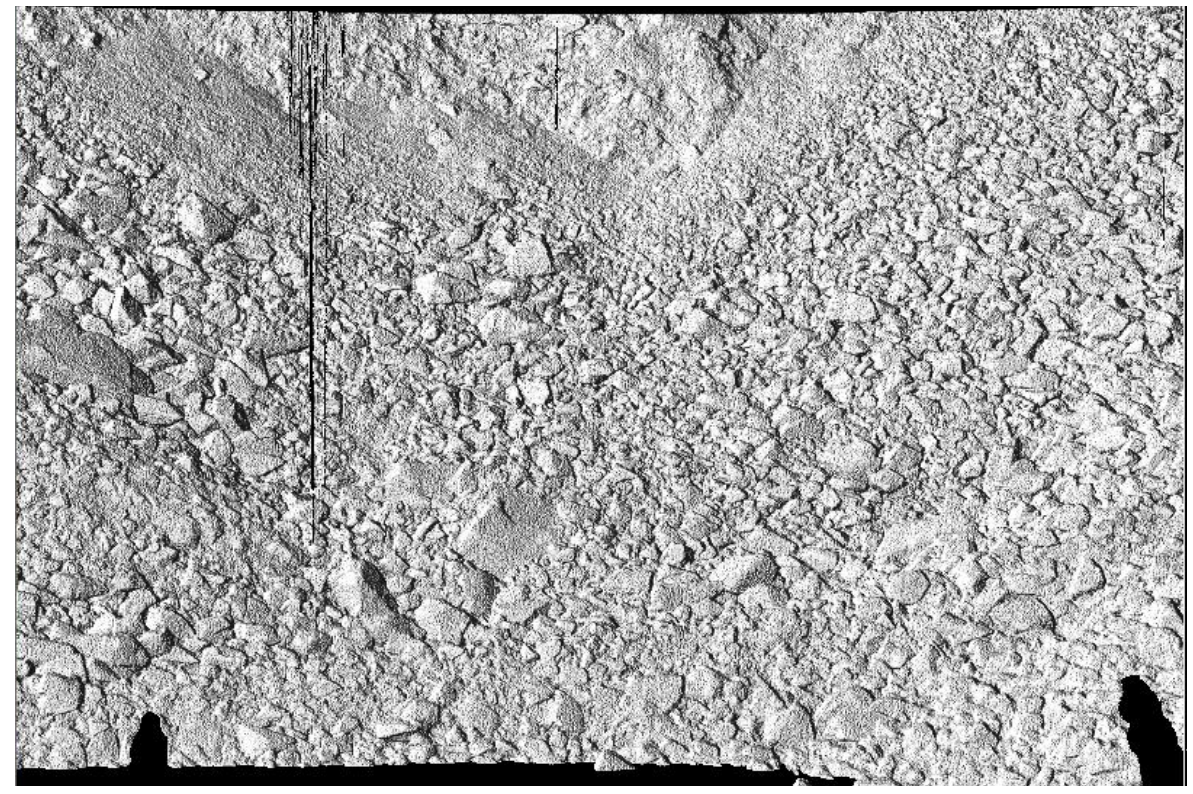

Figure 7. Orthogonal projection of muckpile laser scan 


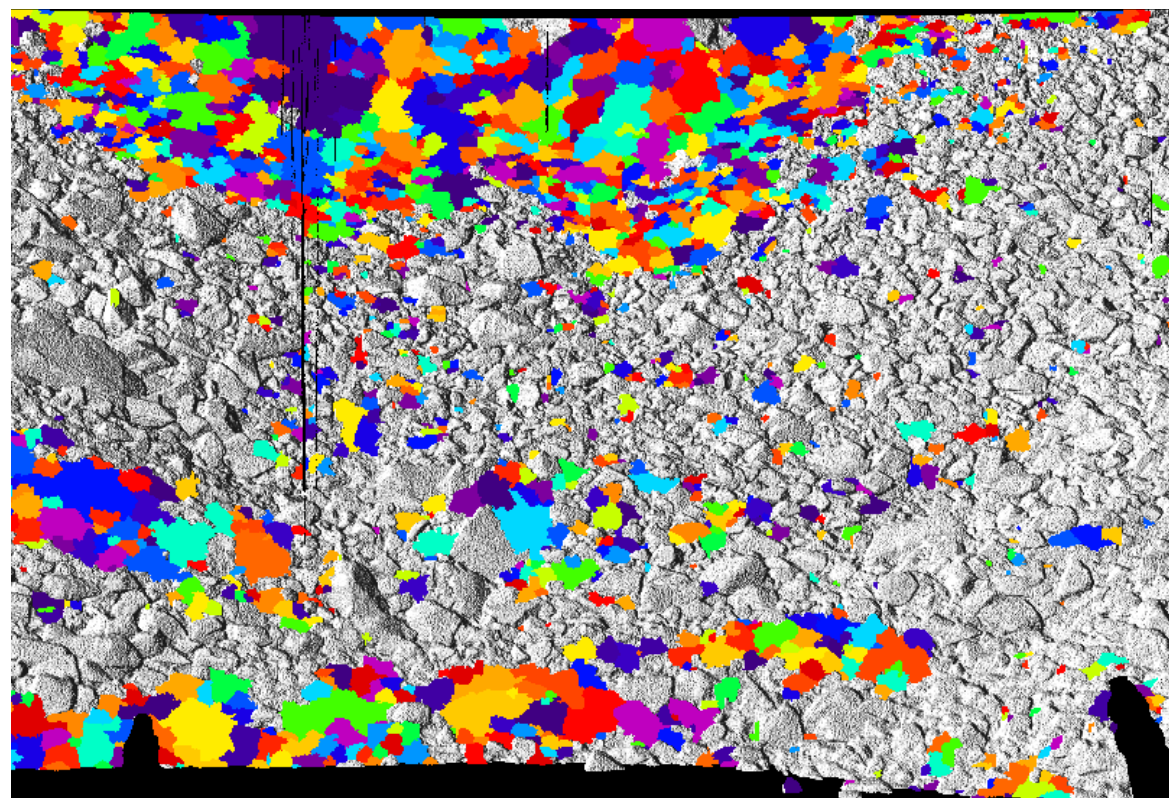

Figure 8. Automatically identified areas-of-fines (shown in color)

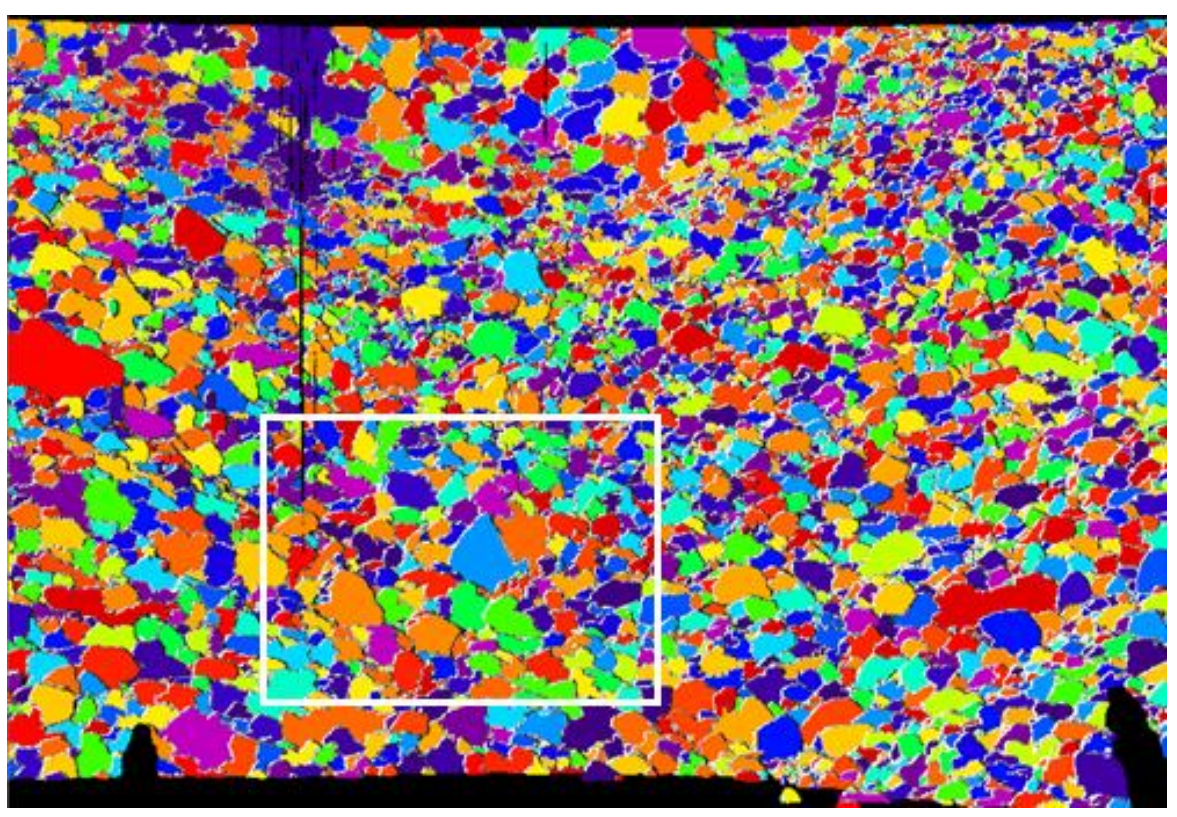

Figure 9. Automatic particle delineation (white box region shown in Figure 10) 


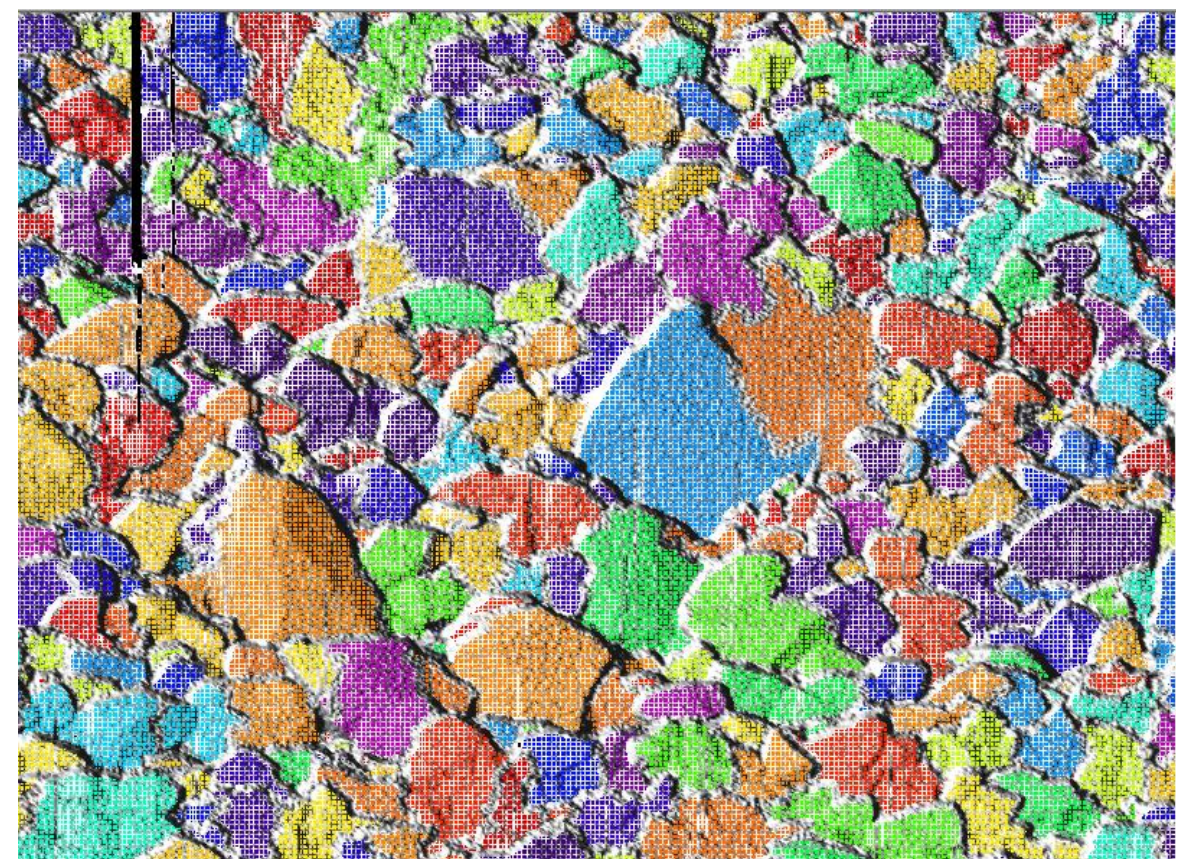

Figure 10 Magnified delineation area for the white box shown in Figure 9

\section{Blast fragmentation measurements}

As discussed earlier, two comprehensive blast performance monitoring campaigns were conducted at Esperanza mine. The first was carried out during January through to March 2013, and the second campaign was conducted during the months of October and November 2013.

The images shown in this paper are based on orthogonally re-projected 3D data. This means that the rocks in the images at the front of the data look larger than they are in reality. This "re-projection" is part of the analysis strategy, but it does not affect the sizing in any way, as the data is projected back to the real perspective view prior to sizing.

\subsection{Results}

Overall results have shown the ability of the algorithms to reliably process high resolution 3D laser scanning data. Fully automated results (i.e. no manual editing) were obtained for the close range data sets.

The analysis showed that if the measurements were taken too far away from the muckpile then the resolution of the data was lower and the algorithms could not identify the areas-of-fines. These areas-of-fines were predominately large areas of compressed fines at the top of the muckpile (as shown in Error! Reference source not found.). Therefore these large areas were manually identified in the 3D data before performing particle delineation.

A review of the data collected showed that in some instances, the pre-defined and recommended data collection procedures outlined in section 4.1 were not followed. Furthermore, some of these data sets in the second campaign were corrupted with distorted, warped, or missing data due to some error with the sensor or sensor operation and these were manually removed.

A key lesson from the measurement trials is the need to ensure consistent and correct operation of the laser scanner to ensure consistent data quality measured in the expected field of view and range of $8-10 \mathrm{~m}$ from the toe of the muckpile. If the rock piles are imaged in this way then fully automatic image analysis of every measurement set can be performed. 


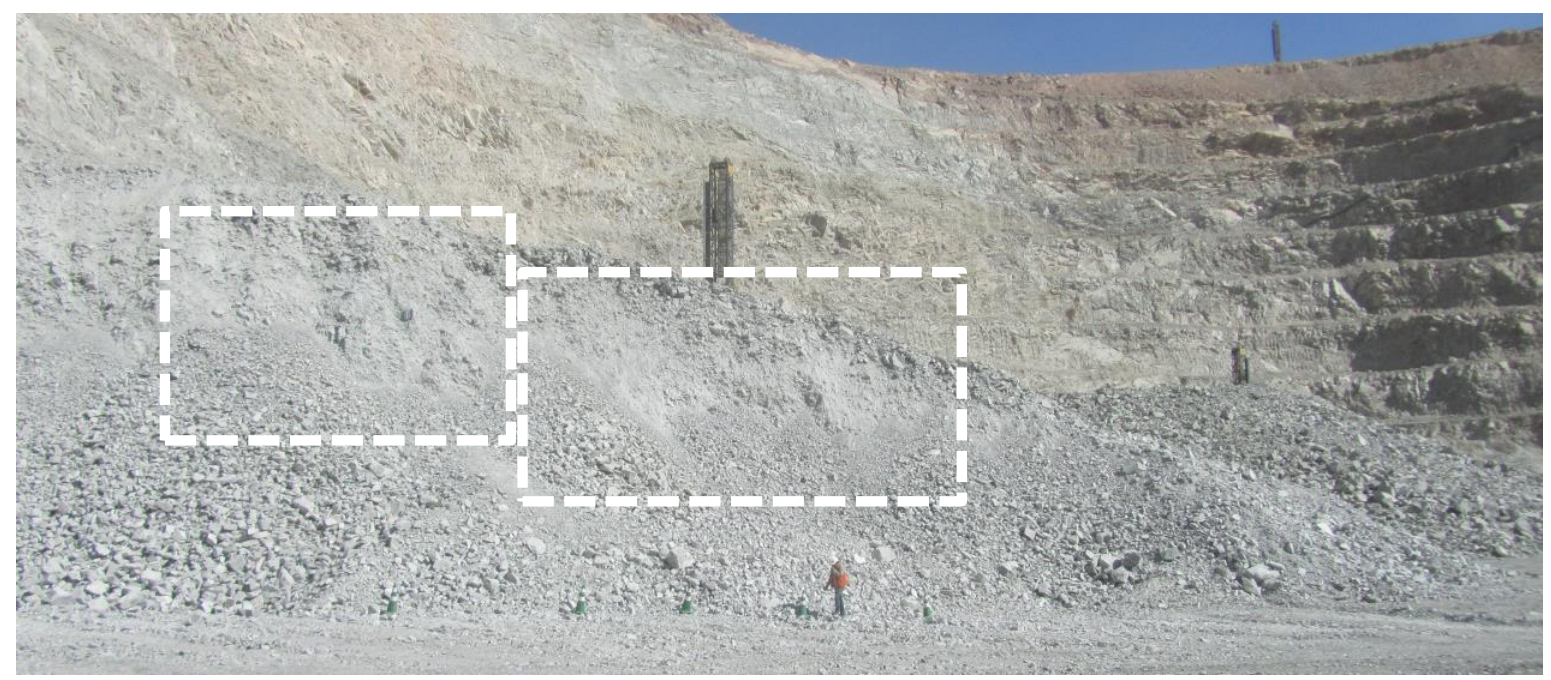

Figure 11. Muckpile showing compressed fines in the upper regions

Using the higher resolution data, automatic delineation of the areas of fines was achieved. An example of this is illustrated in the automated delineation shown in Figure 12. Work is continuing in order to improve the reliability of automated algorithms to delineate regions of compressed fines, but early indications show that by measuring from close range with the expected field of view and appropriate high resolution settings, automated image analysis will produce meaningful particle delineations and consistent results.

As a comparison, Onederra et. al. (2010) performed a larger blast fragmentation assessment using 2D photographic imaging in 2010. Considering Blast ID 3724-10 in Table 3 of that study (Onederra et. al. 2010) we note that scaling objects (long blue pipes with white balls attached) were placed on the muckpile a total of 46 times at different stages of excavation. In each case three sample photographs were taken so that each photo contained at least two of these white balls, resulting in a total of 138 photographs of the muckpile. Figure 13 shows an illustration of 16 instances of the scaling objects on the partly excavated muckpile evaluated by Onederra et. al. (2010) and Figure 14 shows the scaling objects in two of the sample images taken.
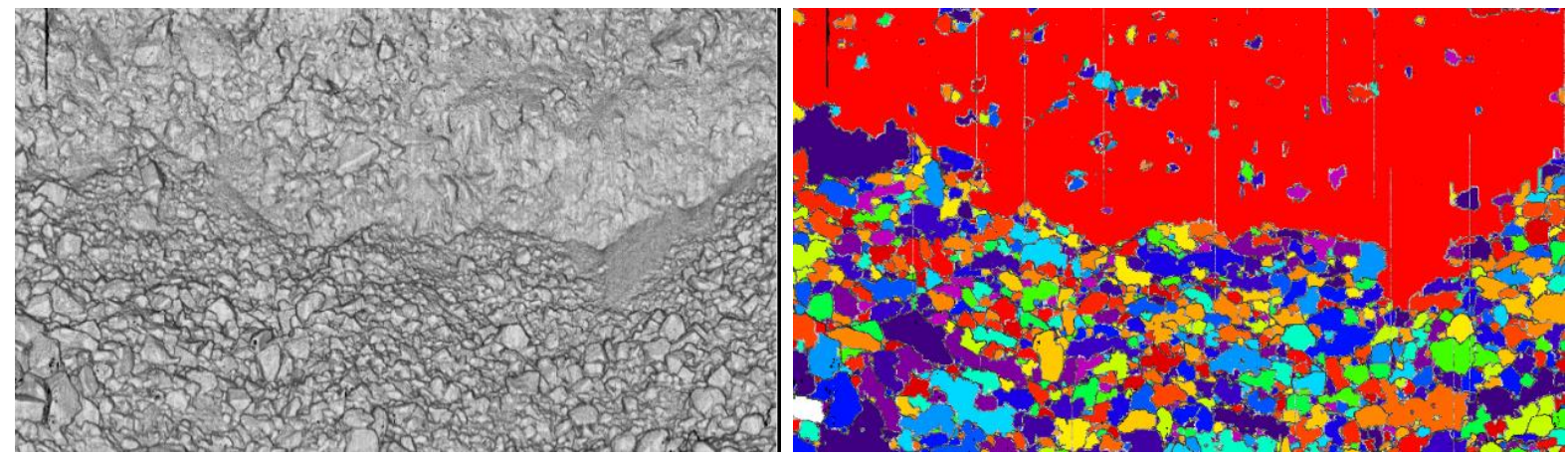

Figure 12. Example of automatic identification of compressed fines (red area) 


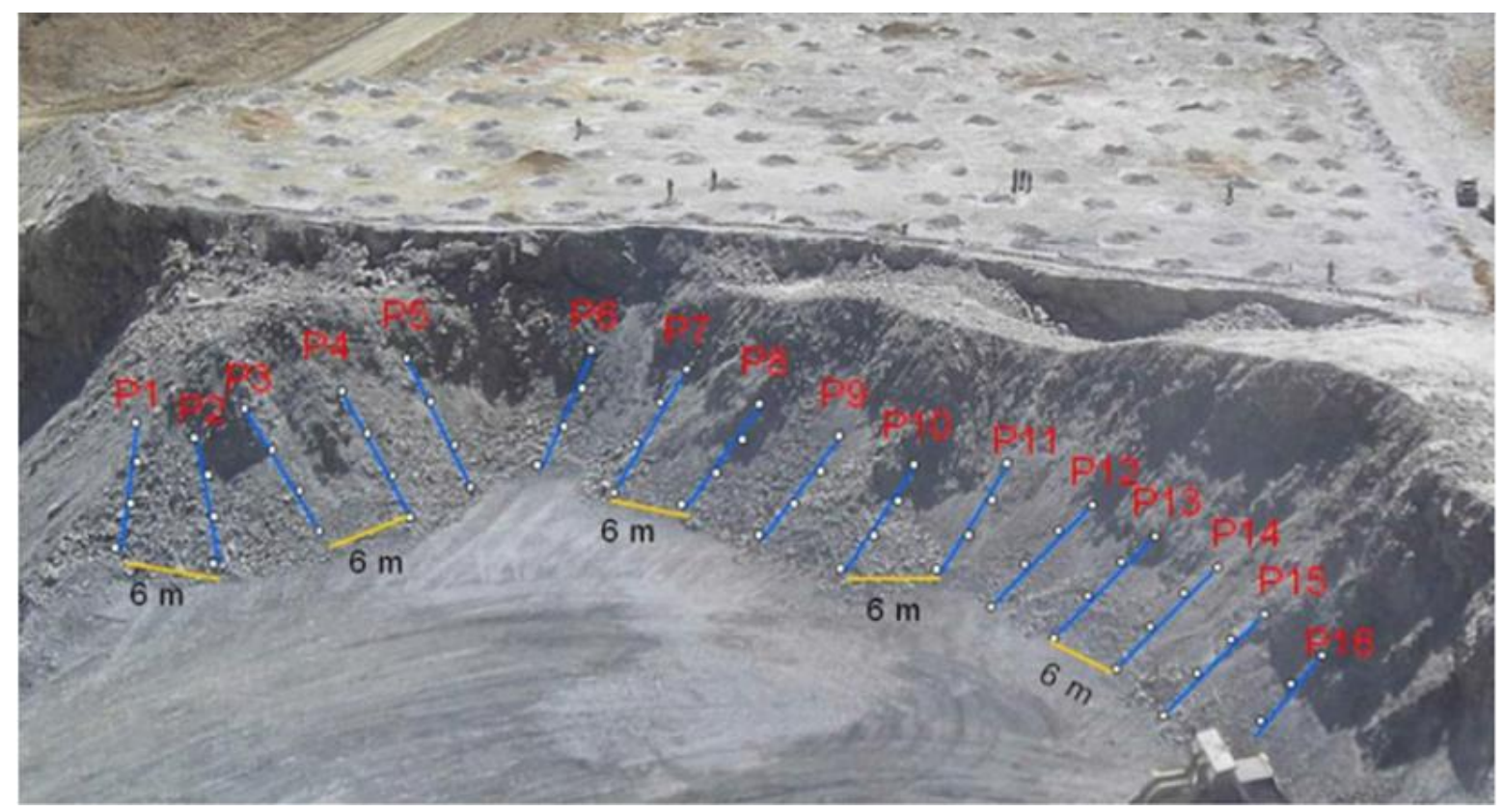

Figure 13. Sixteen scaling object profiles on the muckpile (Onederra et. al. 2010)

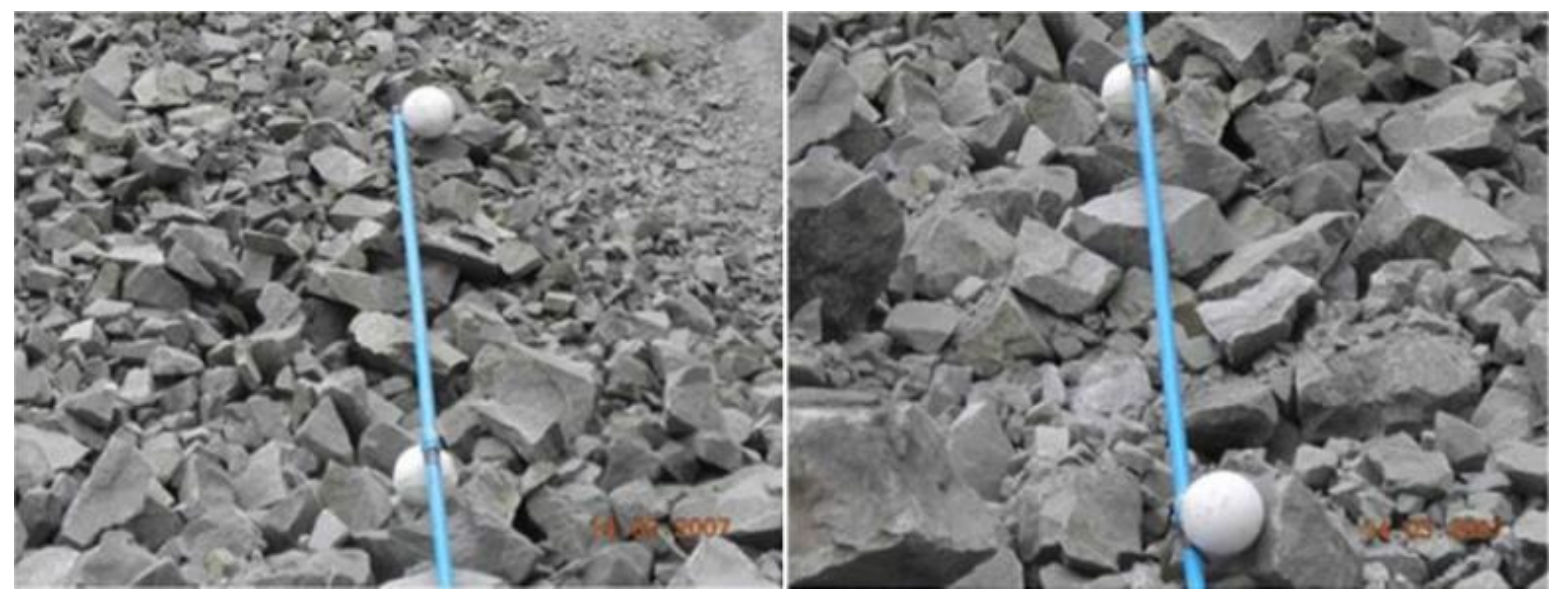

Figure 14. Two sample images each containing two white ball scaling objects (Onederra et. al. 2010)

With the close range high resolution scans outlined in this paper less activity can be performed at the muckpile. In section 4.2 the measurement geometry was detailed and set A (Figure 6) was presented with a horizontal (x axis) extent of $9 \mathrm{~m}$, vertical (y axis) extent of $7 \mathrm{~m}$, and a depth of $15 \mathrm{~m}$. Using simple trigonometry the distance along the muckpile slope is slightly over $16 \mathrm{~m}$ for set $\mathrm{A}$. The blue pole scaling objects in Figure 13 were $12 \mathrm{~m}$ long. Therefore, set A covers an area wider and further up the muckpile slope than the area photographed around one of the blue poles. Based on the dimensions shown in Figure 13, approximately 10 laser scanner sets could cover this same area. Therefore, a total of 30 3D measurements could replace the 138 photographs performed by Onederra et. al. (2010) with no requirement for scaling objects, and the benefit of automated image analysis.

Table 2 provides a summary of tasks to compare fragmentation measurement based on the close range 3D data and the equivalent task using 2D photographic imaging performed by Onederra et. al. (2010). 
Table 2: Comparison of measurement process for 3D laser scanning and 2D photographic imaging

\begin{tabular}{|c|c|c|}
\hline & 3D with presented approach & 2D photographic imaging \\
\hline Pre-configure & $\begin{array}{l}\text { Configure the scanner measurement } \\
\text { settings }\end{array}$ & standard photographic settings \\
\hline \multirow[t]{4}{*}{ Measurement } & $\begin{array}{l}\text { Setup scanner at } \sim 9 \mathrm{~m} \text { from the toe of the } \\
\text { muckpile, }\end{array}$ & $\begin{array}{l}\text { Place scale objects or targets on the } \\
\text { muckpile }\end{array}$ \\
\hline & \multirow{3}{*}{$\begin{array}{l}\text { Initiate scan (works in light or darkness) } \\
\text { Wait for completion then pack up }\end{array}$} & Take photographs (requires day light \\
\hline & & conditions) \\
\hline & & $\begin{array}{l}\text { Remove scale objects from the } \\
\text { muckpile }\end{array}$ \\
\hline \# of Images & $303 \mathrm{D}$ images & 138 images \\
\hline $\begin{array}{l}\text { Manual pre- } \\
\text { analysis steps }\end{array}$ & None & Specify the scale in each image \\
\hline Analysis & Automatic & $\begin{array}{l}\text { Requires extensive manual editing of } \\
\text { the delineation }\end{array}$ \\
\hline
\end{tabular}

An overall comparison of fragmentation measurements taken during the first campaign (January through to March) is given in Figure 15. This analysis provides a representation of the ROM fragmentation outcomes from production blasting in the first campaign (from January to March 2013). The average powder factor from these production blasts was of the order of $480 \mathrm{~g} / \mathrm{t}$.

As shown in Figure 15, direct measurements of fragmentation show that fines (ranged from 53\% to $61 \%$; top sizes (99\% passing fraction) range between $700 \mathrm{~mm}$ and $1800 \mathrm{~mm}$ and $80 \%$ passing fraction (P80) was of the order of $250 \mathrm{~mm}$ to $300 \mathrm{~mm}$. The Marzo 14 curve is a subset of the Marzo 16 curve in Figure 15 and shows the result of combined data sets with two scans removed that each contained a single large boulder that were biasing the overall size distribution curve.

One of the key requirements of mineral processing personnel at Esperanza mine was the ability to estimate the percent passing below 32mm (1//4") from the run of mine (ROM) fragmentation. Previous survey data suggested that the grinding stage performed at close to optimal levels when fines (i.e. $32 \mathrm{~mm}$ ) were above $40 \%$.

It was clear from the analysis that the detection of particles below $32 \mathrm{~mm}\left(1 \frac{1 / 4}{4}\right)$ was mathematically possible but the output from the process algorithms was not reliable at this smaller size, this was mainly due to the limitations on the scanning resolution and scan distances. However as shown in Figure 16, estimates could be made of the expected \% passing fraction below $32 \mathrm{~mm}$. The estimated range was based on a lower and upper bound extrapolation in the log-linear space. After combining all the available data, the simple extrapolation showed that the percent passing below $32 \mathrm{~mm}$ was most likely in the range of $50 \%$ to $58 \%$. This was consistent with observations recorded by mine personnel. 


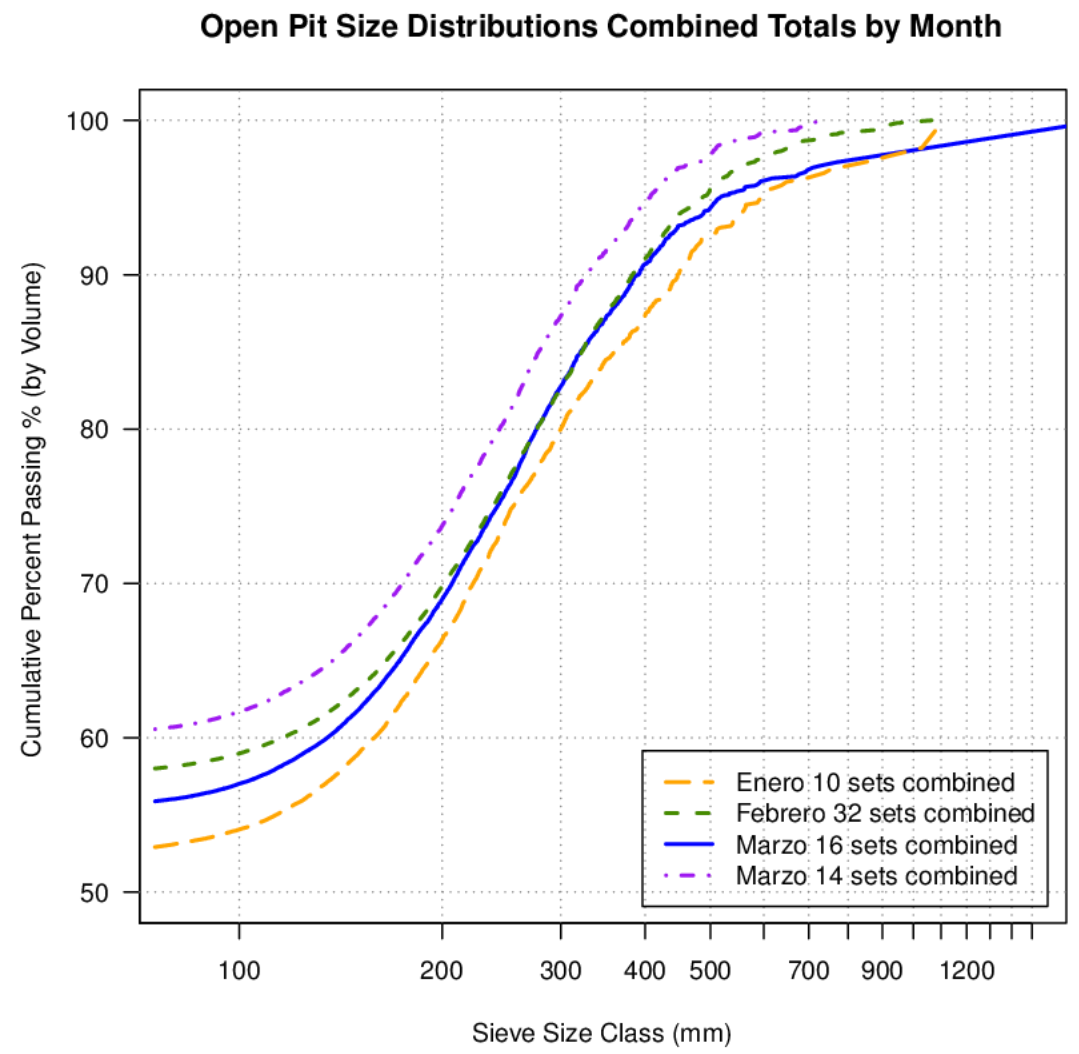

Figure 15. Combined fragmentation results for laser scans taken during the January-March Campaign

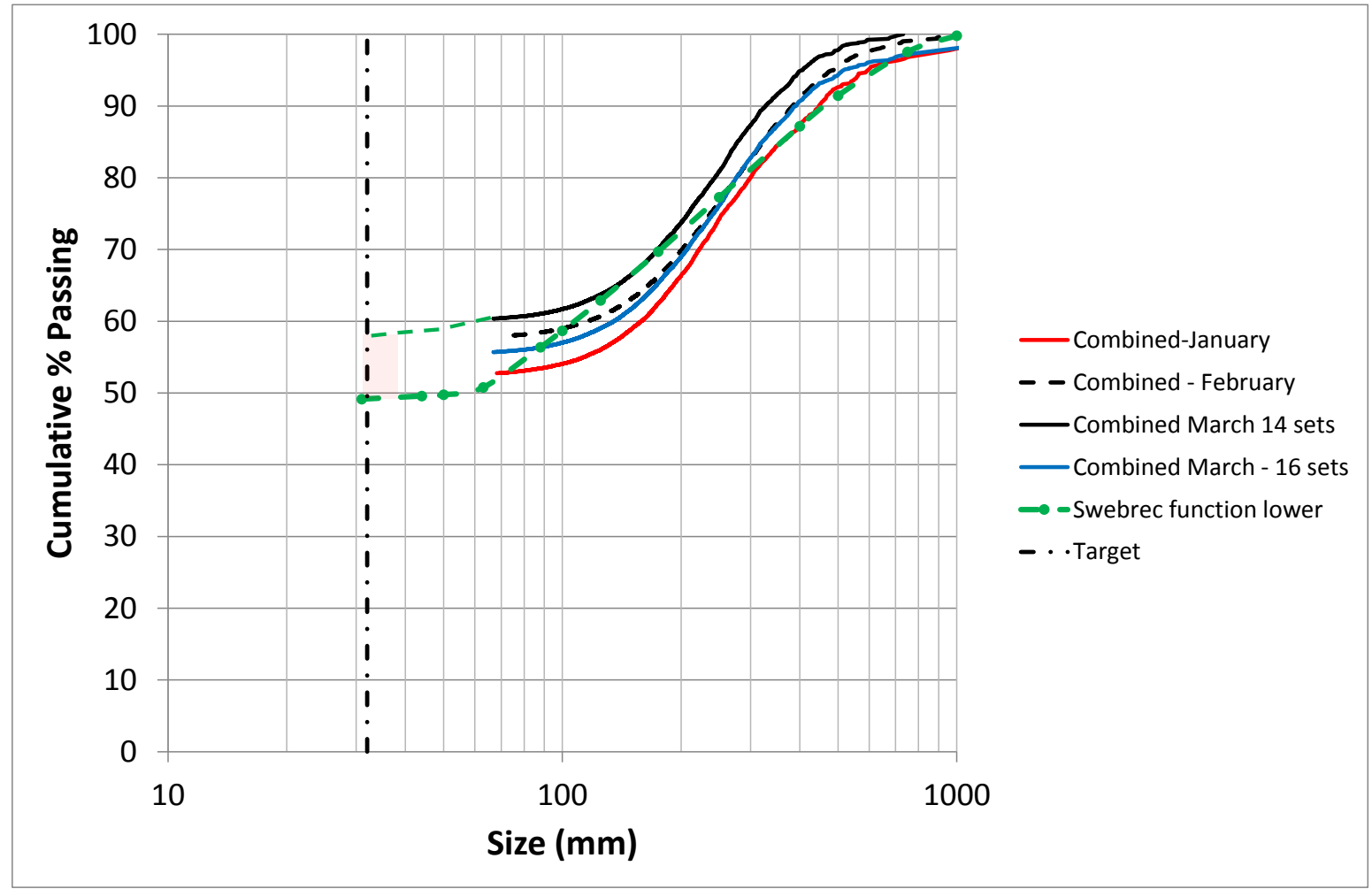

Figure 16. Estimate of expected range of fines below $32 \mathrm{~mm}$ 
During the second campaign which took place in October-November 2013, laser scan data sets were analysed separately for the first two production blasts. The average powder factor for these two blasts was $350 \mathrm{~g} / \mathrm{t}$. Figure 17 shows the combined fragmentation output from the laser scanning analysis of these two blasts. In general, the analysis indicated that the estimated percent passing below $32 \mathrm{~mm}$, based on a lower and upper bound extrapolation was in the range of $49 \%$ to $59 \%$. The estimated top sizes (99\% passing fraction) ranged between $840 \mathrm{~mm}$ and $1300 \mathrm{~mm}$ with the $80 \%$ passing fraction (P80) for both blasts being of the order of $300 \mathrm{~mm}$. Images of muckpiles taken immediately after the blasts are shown in Figure 18.

A marked difference and somewhat unexpected coarser fragmentation output was found after analysing the data set of a third blast in this second campaign. This was attributed to marked changes in geological conditions and some deficiencies found in the data collection process which affected sampling. Figure 19 gives the output corresponding to the laser scanning analysis of the third data set relative to the more consistent sampling taken from the first two blasts in this domain. This output shows the ability of the process algorithms to automatically identify relative changes in fragmentation outcomes.

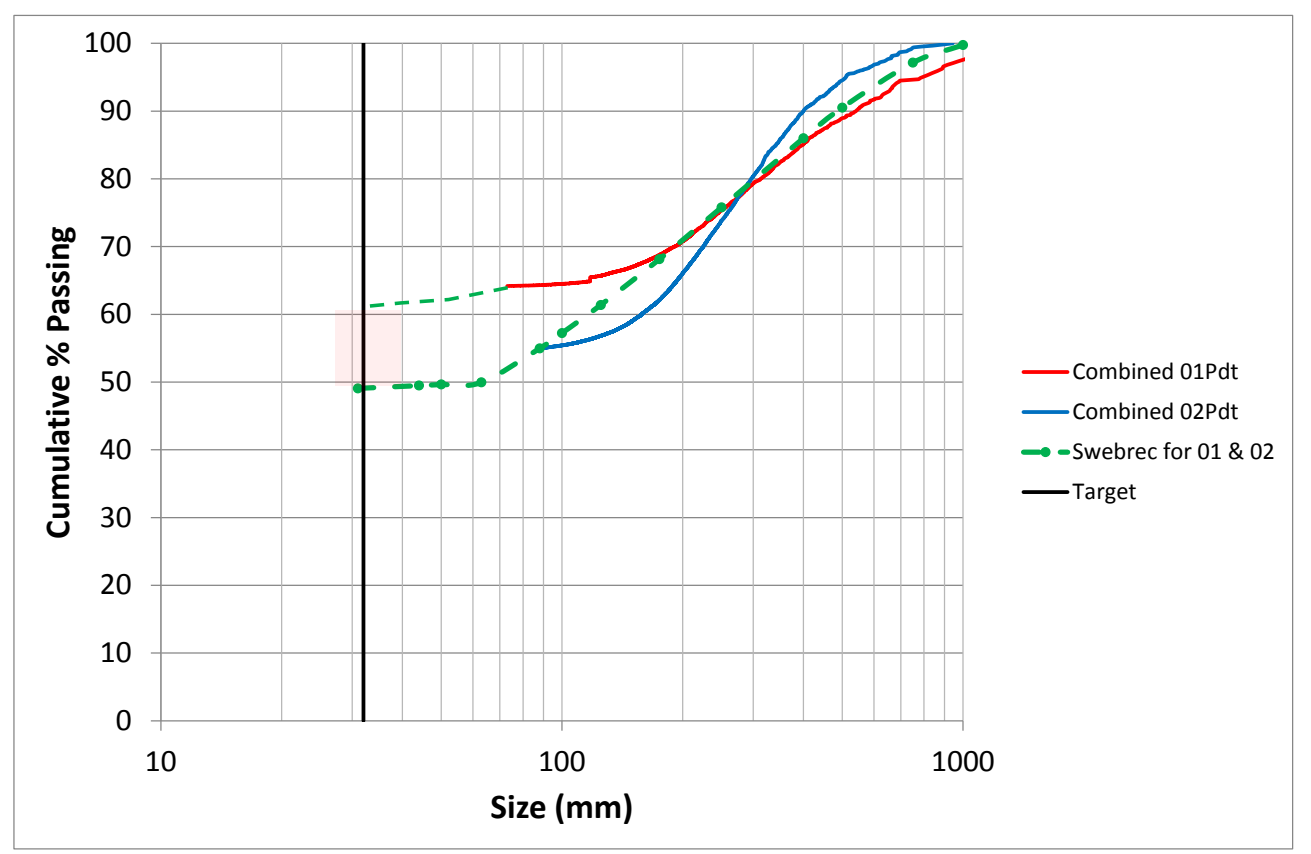

Figure 17. Combined output of data sets from blasts with an average powder factor of $350 \mathrm{~g} / \mathrm{t}$ 

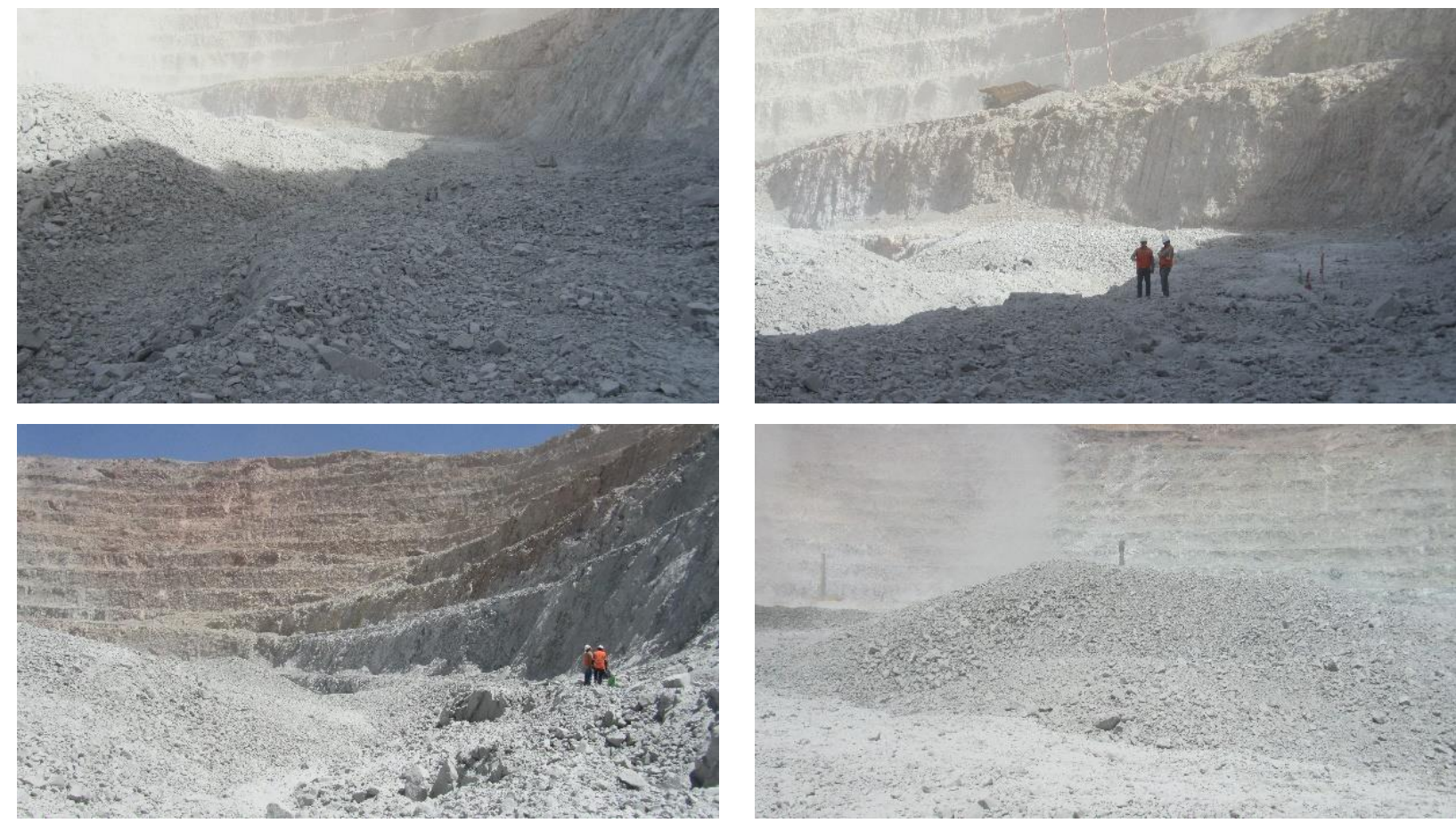

Figure 18. Typical muckpile photographs for two blasts from the second campaign

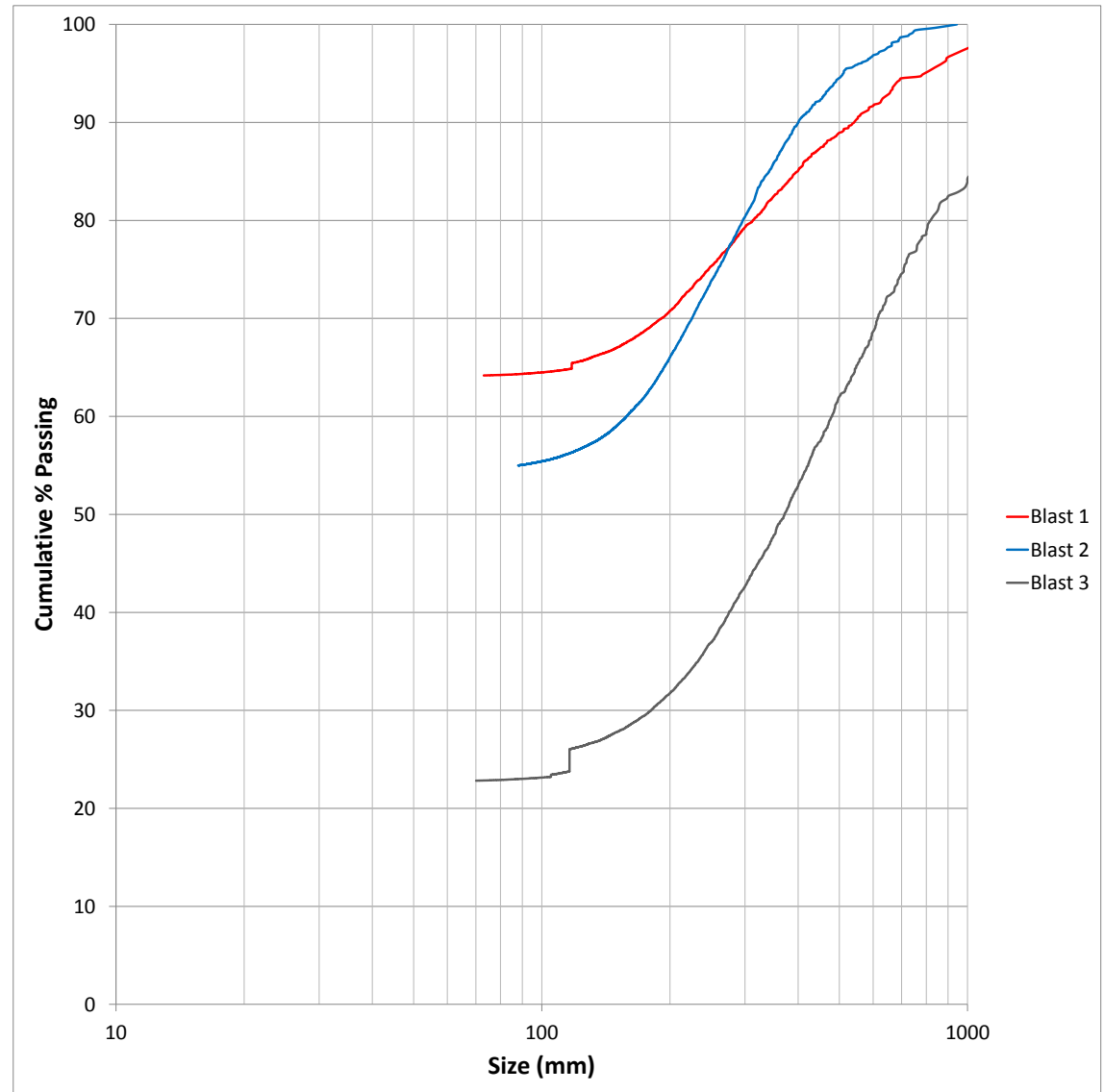

Figure 19. Fragmentation output from all three blasts in the second campaign. Note coarser fragmentation outcome from blast 3 
As with the previous campaign and regardless of the potential bias, all data sets were combined to obtain overall fragmentation results corresponding to three production blasts with an average powder factor of $360 \mathrm{~g} / \mathrm{t}$. The combined curve is given in Figure 20. The output from this analysis indicated that the estimated $\%$ passing below $32 \mathrm{~mm}$, would be approximately $42 \%$. The estimated top size (99\% passing fraction) was of the order of $1690 \mathrm{~mm}$ and the $80 \%$ passing fraction (P80) of the order of $450 \mathrm{~mm}$.

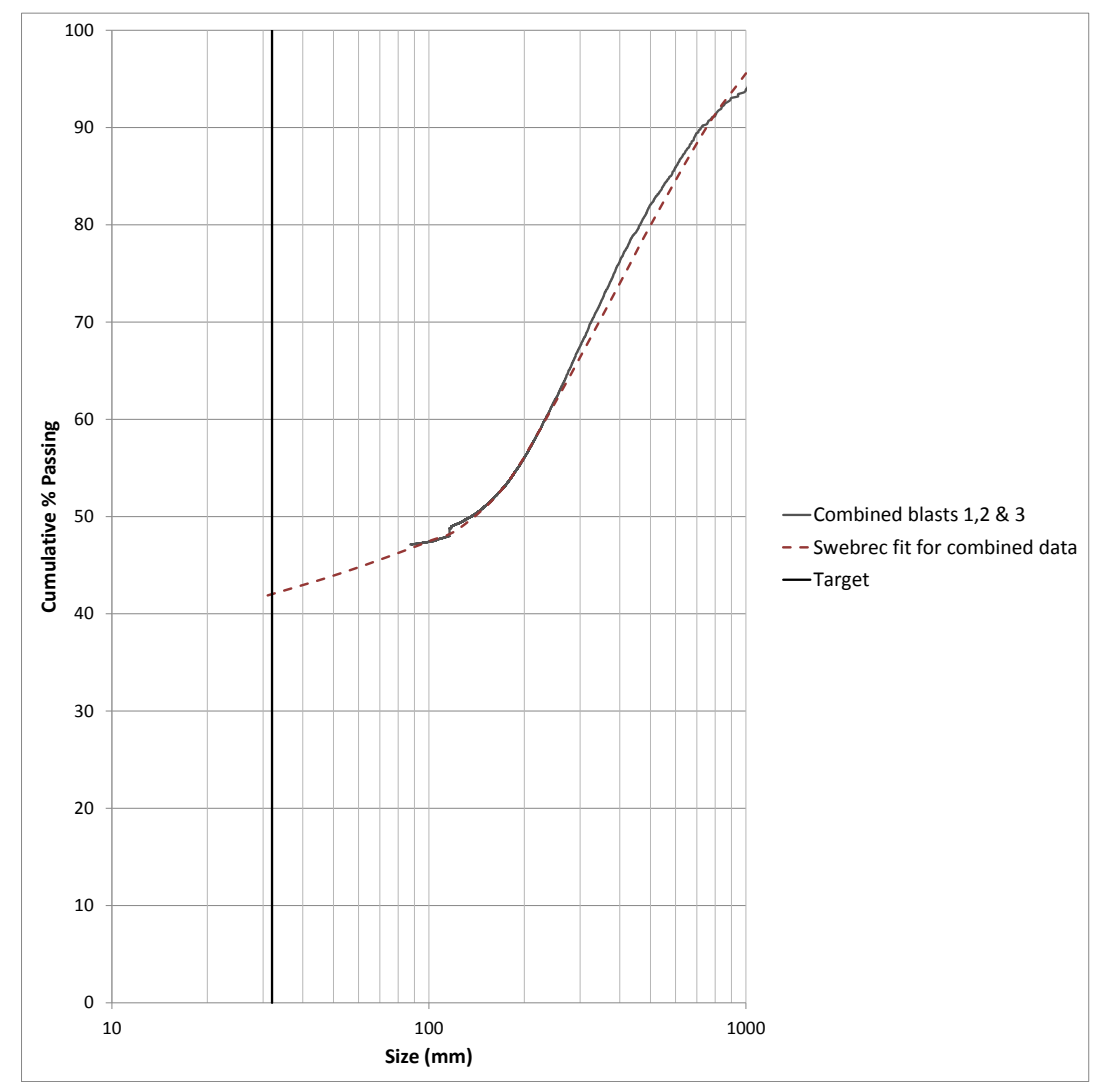

Figure 20. Combined data sets representing ROM fragmentation from the second campaign

\section{Conclusions and future work}

A new technique was adopted at Esperanza mine to measure run of mine (ROM) fragmentation. This involved high resolution laser scanning of muckpiles together with the application of improved detection and delineation algorithms. This technique addressed many of the shortcomings of 2D image based systems currently used in industry. Part of the implementation process involved site specific data collection procedures with the use of the I-site Maptek laser scanner available at Esperanza Mine.

Fully automated analysis of the 3D data was possible in all cases where the data was of sufficiently high resolution (collected from approx. $9 \mathrm{~m}$ from the toe of the muckpile). Manual pre-processing was required when the data was of low resolution (measured from too far away) in order to specify the region of fines; or was damaged (corrupted) during the collection process. 
Laser scanning data was collected over a period of 3 months in the first campaign which corresponded to blasts with an average powder factor of $480 \mathrm{~g} / \mathrm{t}$. The detection of particles below $32 \mathrm{~mm}\left(1 \frac{1 / 4}{\prime \prime}\right)$ was mathematically possible but the output from the process algorithms was not reliable at this smaller size, mainly due to the limitations on the scanning resolution. By applying a lower and upper bound extrapolation in the log-linear space, the combined analysis from this monitoring campaign showed that the expected percent passing fraction below $32 \mathrm{~mm}$ was in the range of 50\% to 58\%; top sizes (99\% passing fraction) ranged between $700 \mathrm{~mm}$ and $1800 \mathrm{~mm}$; and the $80 \%$ passing fraction (P80) was of the order of $250 \mathrm{~mm}$ to $300 \mathrm{~mm}$.

In the second monitoring campaign laser scanning data was collected across blasts with an average powder factor of $360 \mathrm{~g} / \mathrm{t}$. It was evident that the first two blasts approached conditions similar to those measured during the first monitoring campaign with a notable reduction in powder factor. The combined fragmentation output of these two blasts indicated that the estimated \% passing below $32 \mathrm{~mm}$ was in the range of $49 \%$ to $59 \%$. The estimated top size (99\% passing fraction) ranged between $840 \mathrm{~mm}$ and $1300 \mathrm{~mm}$ with the $80 \%$ passing fraction (P80) for both blasts being of the order of $300 \mathrm{~mm}$.

An unexpected coarser fragmentation output was found after analysing data sets from a third blast which was conducted in a different domain. The combined curve for all three blasts monitored in the second campaign indicated that the estimated $\%$ passing below $32 \mathrm{~mm}$ was approximately $42 \%$. The estimated top size $(99 \%$ passing fraction was of the order of $1690 \mathrm{~mm}$ and the $80 \%$ passing fraction (P80) approximately $450 \mathrm{~mm}$.

Table 3 provides a summary of key fragmentation indicators from this monitoring campaign. Overall results indicated that ROM fragmentation requirements were consistently meeting specified targets despite the differences in powder factors. This was the case for those blasts conducted in similar blasting domains. The identified bias from the third blast in campaign two is clear in the coarse end statistics showing a marked increase in P80 and top size.

Table 3: Size Distribution Results

\begin{tabular}{lllccc}
\hline $\begin{array}{l}\text { Monitoring } \\
\text { Campaign }\end{array}$ & $\begin{array}{l}\text { Number of } \\
\text { production } \\
\text { blasts }\end{array}$ & $\begin{array}{l}\text { Average powder } \\
\text { factor }(\mathbf{g} / \mathbf{t})\end{array}$ & $\begin{array}{c}\text { \% passing below } \\
\text { 32 } \mathbf{m m}(\boldsymbol{\%})\end{array}$ & $\begin{array}{c}\text { 80\% passing } \\
(\mathbf{m m})\end{array}$ & $\begin{array}{c}\text { 99\% passing } \\
(\mathbf{m m})\end{array}$ \\
\hline 1 & 3 & 480 & $50-58$ & $250-300$ & $700-1800$ \\
2 & 2 & 350 & $49-59$ & 300 & $840-1300$ \\
$2 \mathrm{~B}^{*}$ & 3 & 360 & 42 & $\sim 450$ & $\sim 1690$ \\
\hline
\end{tabular}

*note that data was combined with a suspected sampling bias and blast domain incompatibility

This work has demonstrated that high resolution laser scanning can be used as an alternative technique to measure "whole of muckpile" ROM fragmentation in production blasting. Although limitations were found with the quantification of compressed fines, relative comparisons were possible. Current limitations are being addressed by defining procedures that involve estimating fines with measurements taken from both the source muckpile and the primary crusher product. This procedure will use proven and commercially available laser based measurement systems and material tracking devices.

Data collection procedures may vary depending on accessibility and site conditions. Further work is required to standardise data collection procedures to improve processing speed and output reliability. 


\section{Acknowledgements}

The authors would like to thank Antofagasta Minerals for allowing the publication of this work. We would also like to acknowledge the support in the data collection process provided by Esperanza mine personnel in particular Ignacio Campos and Patricio Lagos.

\section{References}

Carlsson O. and Nyberg L. (1983), "A method for estimation of fragmentation size distribution with automatic image processing," in Proceedings of the First International Symposium on Rock Fragmentation by Blasting- FRAGBLAST, Lulea, Sweden, August 1983, pp. 333-345.

Delille F., Goetz, F. and Tessier, B. (2013) "Return on experience from full-scale open pit blasting experiments", in Measurement Measurement and Analysis of Blast Fragmentation. Workshop at FRAGBLAST 10 - The 10th International Symposium on Rock Fragmentation by Blasting. Dehli, India: CRC Press/Balkema, November 2012, pp 107114, ISBN 978-041562140-3

Maptek (2014) . http://www.maptek.com/products/i-site/

Noy M.J.,(2006) "The latest in on-line fragmentation measurement - stereo imaging over a conveyor," in Proceedings of the Eighth International Symposium on Rock Fragmentation by Blasting - FRAGBLAST 8, May 2006, pp. 61-66.

Noy M.J., (2013) "Automated rock fragmentation measurement with close range digital photogrammetry," in Measurement and Analysis of Blast Fragmentation. Workshop at FRAGBLAST 10 - The 10th International Symposium on Rock Fragmentation by Blasting. Dehli, India: CRC Press/Balkema, November 2012, pp. 13-21, ISBN 978-041562140-3.

Onederra, I, Mardones, F. \& Scherpenisse, C. 2010. Application of stochastic approach to blast fragmentation modelling. Mining Technology, vol 119, no 4, 221-232.

Ord, A.(1988) "Real-time image analysis of size and shape distributions of rock fragments," in Explosives in Mining Workshop. Melbourne: The AusIMM, November 1988, pp. 115-119.

Potts G. \& Ouchterlony F. (2005), The capacity of image analysis to measure fragmentation, an evaluation using split desktop. Swebrec - Swedish Rock Breaking Institute, Technical Report, 2005, ISSN 1653-5006.

Rosato, A., Strandburg K., Prinz F., and Swendsen R., (1987) "Why the brazil nuts are on top: Size segregation of particulate matter by shaking," Physical Review Letters, vol. 58, no. 10, pp. 1038-1040, 1987.

Thurley M.J. and Ng, K.C. (2005) "Identifying, visualizing, and comparing regions in irregularly spaced 3D surface data," Computer Vision and Image Understanding, vol. 98, no. 2, pp. 239-270, February 2005.

Thurley, M \& Ng, K (2008), 'Identification and sizing of the entirely visible rocks from a 3D surface data segmentation of laboratory rock piles' Computer Vision and Image Understanding, vol 111, no. 2, pp. 170-178.

Thurley M.J. (2009), "Fragmentation size measurement using 3D surface imaging (in LHD buckets)," in Proceedings of the Ninth International Symposium on Rock Fragmentation by Blasting - FRAGBLAST 9, Granada, Spain, September 2009, pp. 133-140. 
Thurley M.J., (2011) “Automated online measurement of limestone particle size distributions using 3D range data," Journal of Process Control, vol. 21, no. 2, pp. 254-262,

Thurley M.J. (2012) "Automated, on-line, calibration-free, particle size measurement using 3D profile data," in Measurement and Analysis of Blast Fragmentation Workshop at FRAGBLAST 10 - The 10th International Symposium on Rock Fragmentation by Blasting. Dehli, India: CRC Press/Balkema, November 2012, pp. 23-32, ISBN 978-041562140-3.

Thurley, M. (2013) "Automated image segmentation and analysis of rock piles in an open-pit mine“, 2013 International Conference on Digital Image Computing: Techniques and Applications (DICTA 2013): Hobart, Australia, 26-28 Nov. 2013 .Piscataway, NJ: IEEE, 8 p. 6691484

Venkatesh, H.S., Vamshidhar, K., Gopinath, G., Theresraj, A.I., \& Balachander, R. (2013) "Optimisation of blast design for an iron ore mine and assessment of fragmentation through image processing" in Measurement and Analysis of Blast Fragmentation. Workshop at FRAGBLAST 10 - The 10th International Symposium on Rock Fragmentation by Blasting. Dehli, India: CRC Press/Balkema, November 2012, pp. 123-131, ISBN 978-041562140-3. 